\title{
PSMA/TARP Peptide Vaccine
}

National Cancer Institute

\section{Source}

National Cancer Institute. PSMA/TARP Peptide Vaccine. NCI Thesaurus. Code C78819.

A peptide-based cancer vaccine containing epitopes of $\mathrm{T}$ cell receptor gamma-chain alternate reading frame protein (TARP) and prostate-specific membrane antigen (PSMA) in combination with a Poly IC-LC immunoadjuvant, with potential antineoplastic activity. Upon administration, PSMA/TARP peptide vaccine may stimulate a host cytotoxic T-cell (CTL) response against TARP- and PSMA-expressing tumor cells, resulting in tumor cell cytotoxicity. The nuclear protein TARP and PSMA are commonly expressed in prostate cancer cells. 